\title{
CONTRIBUCION AL VOCABULARIO ESPAÑOL DEL SIGLO XVI
}

\author{
F. GONZÁLEZ OLLÉ *
}

Al dar a conocer, hace años, la obra Guerras civiles de Flandes, de Alonso de Pimentel, ${ }^{1}$ cuya composición transcurrió de 1587 a 1598 , señalé su interés lexicográfico, pero no pude entonces ocuparme de este aspecto del poema.

Al hacerlo ahora, ${ }^{2}$ debo recordar que la materia de Guerras civiles de Flandes está constituida fundamentalmente por las experiencias personales del autor a través de su larga vida militar en Italia y Flandes. Pimentel narra sin apenas aliento poético, pese a la forma dada a su relato. Le preocupan, ante todo, la verdad, la objetividad, el detalle de los hechos y sus circunstancias, hasta el punto de anotar marginalmente sus propios versos. De ahí la llaneza de su estilo, que cae con frecuencia en el desaliño y aun en la incorrección; y también, puede suponerse, la espontaneidad de su vocabulario. En efecto, abundan de modo natural los términos particulares de la milicia e igualmente vocablos propios de los países que recorrió, como si Pimentel respondiese a una actitud que, en determinado momento, refiere, con ironía, de forma explícita: Es menester que cada día / váis usando la lengua generosa / que se platica y dice en Lombardía $(238 v)$. En algunos casos, el autor denuncia directa o indirectamente la novedad léxica que ha admitido. Otras palabras empleadas en la obra,

\footnotetext{
* Universidad de Navarra.

1 F. González Ollé, "Guerras civiles de Flandes», poema épico inédito. BRAE, $1965,45,141.84$.

2 De un campo muy concreto me he ocupado ya en mi estudio Nuevos testimonios tempranos de pícaro y palabras afines. Iberoromania, 1969, 1, 56-8. Sobre el interés de estos materiales, puede verse el juicio de Y. Malkiel en su artículo El núcleo del problema de pícaro-picardía. En torno al proceso del préstamo doble, en Studia Hispanica in bonorem R. Lapesa. Madrid, 1974, II, 321.
} 


\section{F. GonzÁlez Ollé}

castizas y usuales, figuran en diccionarios, pero no han sido hasta ahora documentadas con textos.

En el presente estudio recojo aquellas palabras de Guerras civiles de Flandes que, en el estado actual de la lexicografía española (en la medida en que me es conocido y consciente del riesgo que siempre comporta señalar prioridades cronológicas), están nula o escasamente atestiguadas o fechadas posteriormente o tenidas por arcaísmos en época de Pimentel. También incluyo las utilizadas con acepciones no registradas hasta el momento y aquellas cuyo etimología permanece sin resolver, en especial si se presentan como variantes de la forma más generalizada. Particular atención dedico, por el interés que ofrecen para la historia del léxico, a las procedentes del neerlandés, ${ }^{3}$ del alemán o del francés (brindis, dique, enclusa, paquete, reistre, trineo, urca, etc.), muchas de las cuales anticipan notablemente la data de aparición conocida.

He excluido, con escasísimas excepciones, los numerosos italianismos adoptados por Pimentel, que merecen un estudio independiente.

La extensión de mis comentarios, que he procurado reducir al mínimo,

3 Para la metodología del estudio de estos préstamos, resulta fundamental el artículo de B. E. Vidos, Relaciones antiguas entre España y los Países Bajos y problemas de los préstamos bolandeses (flamencos) en castellano. RFE, 1972, 55, 233-42. Según Vidos, «dado que en los Países Bajos, en los siglos XVI y XVII, bajo la soberanía española, el castellano era de uso corriente junto al francés (valón) y al holandés (flamenco), lenguas oficiales aún hoy, las palabras holandesas (flamencas) presentes asimismo en el francés, pudieron llegar al español procedentes de éste y no directamente del holandés. Por lo tanto, el que una palabra española conste en un documento de la época de las guerras de Flandes o en una crónica de las mismas, no es suficiente para afirmar que haya pasado al español directamente del holandés, por existir dicha palabra de antiguo, o al mismo tiempo también en el francés» (236). La conclusión de su estudio viene a coincidir con las afirmaciones anteriores: «Como en francés existen más de 800 voces de procedencia holandesa y dado que en los Países Bajos, en los siglos XVI y XVII, nos hallamos en un ambiente francés-holandés (flamenco)-español y que, en la parte meridional de estos países, el francés era entonces de uso general y corriente, es fácil comprender que las voces holandesas llegasen al castellano a través de este gran almacén de palabras holandesas que es el francés. Queda, pues, una cantidad ínfima de palabras españolas que proceden con seguridad directamente del holandés» (242).

Entre los ejemplos expuestos por Vidos figura finanzas, que no documenta hasta Calderón: «El castellano tomó prestada la voz francesa finances en los Países Bajos meridionales, es decir, en Bélgica, en el ambiente franco-español allí existente ya a principios del siglo XVII [...] La institución nacional Conseil des Finances fue conocida entre los españoles en el siglo XVII por Consejo de Finanças en lugar de serlo con la denominación española Consejo de Hazienda» (237). Cfr. finanzas, en el presente estudio, s.v.

En el artículo de Vidos puede verse la bibliografía pertinente sobre los préstamos en cuestión. Añádanse dos breves notas monográficas: A. Van Dam, Lope de Vega y el neerlandés. RFE, 1927, 14, 282-6, y J. E. Gillet, El flamenco en algunos textos españoles antiguos. RFE, 1928, 15, 384-8. 
está en razón de la importancia concedida a la presencia de cada palabra No siempre justifico la inclusión de las consignadas, pero el experto 1^ encontrará de inmediato con la consulta a las fuentes ordinarias de información Jexicográfica.

De éstas, cito abreviadamente las siguientes:

Almirante $=\mathrm{J}$. Almirante, Diccionario militar. Madrid, 1869.

Alonso de Palencia $=$ Alonso de Palencia, Universal vocabulario en latín $y$ en romance. Sevilla, 1490.

Corominas $=\mathrm{J}$. Corominas, Diccionario crítico etimológico de la lengua castellana. Madrid, 1954.

Covarrubias $=\mathrm{S}$. Covarrubias, Tesoro de la lengua castellana o española. Madrid, 1611.

Dicc. Aut. = Diccionario [de autoridades] de la lengua castellana... Madrid, 1726-39.

Dicc. Acad. = Real Academia Española, Diccionario de la lengua española. Madrid, $1970 .^{19}$

Terlingen $=\mathrm{J} . \mathrm{H}$. Terlingen, Los italianismos en español... Amsterdam, 1943.

Los versos de Guerras civiles de Flandes que se citan como testimonio de cada artículo, llevan una triple notación (la primera y segunda en números romanos, la tercera en arábigos) para indicar la parte, el canto y la estrofa en que se encuentran; los pasajes en prosa llevan una sola notación (en números arábigos) para indicar el folio en que figuran.

\section{agarrochado}

'Herido por garrocha'. Más que bace el toro agarrochado, III, $\mathrm{V}, 23$.

No conozco testimonios literarios de esta palabra.

\section{agonía}

'Prisa', 'apremio'. No estuvieron, pues, mucho alli parados, / que Mondragón, con muy grande agonía, / bizo en orden estén aparejados, II, IV, 41.

\section{aguanoso}

'Empapado de agua'. Por ser de la bumedad [tierra] tan aguanosa, I, I, 35.

\section{aguar}

'Frustrar'. Porque no se les agüe gozo y gloria, I, VIII, 1.

\section{alabastrino}

'Semejante al alabastro'. El rostro alabastrino, I, I, 50.

\section{alampar}

'Abrasar'. El fuego / me alampe cuando estén sus llamas ricas, III,II,17.

Según Corominas, está difundido por toda España (a)(l)lampar 'sentir ardor en el paladar', 'sentir ansia de comer o beber', 'ansiar', que, en la forma lampar, documenta por primera vez 


\section{F. GonzÁlez Ollé}

en el P. Isla (1758). Aunque en última instancia remonte al helenismo latino lampas 'antorcha', por lo tardío de su documentación no cree Corominas, en espera de un estudio más detenido, que sea voz hereditaria en castellano, sino procedente del italiano allampare 'arder'. El presente testimonio de Pimentel adelanta en dos siglos la fecha de aparición $y$, por otra parte, presenta el sentido recto originario, que no aparece en los restantes testimonios peninsulares conocidos hasta ahora.

Estos nuevos datos no constituyen óbice, desde el lado español, para que sea italianismo, dada la variedad de vocablos de esta naturaleza que emplea $\mathrm{Pi}$ mentel. Sí me parece, en cambio, una dificultad la tardía documentación en italiano. Corominas no la encuentra hasta el siglo XVIII, en el vocabulario de la Crusca, lo cual, en efecto, como él advierte, no prueba que su uso no viniera de mucho antes. Pero ahora esa posibilidad queda muy debilitada por el hecho de que el Grande Dizionario della lingua italiana no la atestigüe, en textos, hasta el siglo presente.

\section{alombra}

'Alfombra'. El suelo de alombras adornaron, III, I, 30 .

En la segunda mitad del siglo XVI prevalece ya la forma actual alfombra. amaro

'Amargo'. Lo dulce, lo sabroso con lo amaro, $236 \mathrm{v}$.

\section{amplo}

'Amplio'. No se ba visto jamás misericordia / tan ampla, como el Felipe ba usado, III, IV, 74. Han tractado / de aquesta discrepción tan amplamente, I, I, 18.

\section{ancorado}

'Sujeto con áncora', 'anclado'. Cbarrias anchoradas / $y$ otros vaxeles, III, IV, 60.

\section{anchuroso}

'Ancho', 'dilatado'. Las anchurosas / promesas que el de Orange le ba ofrecido, III, I, 1. No conozco testimonios anteriores.

\section{anja}

'Zanja'. Cada uno tray su pica de manera / que las anjas $y$ arroyos va saltando, II, VI, 25 . No he encontrado ningún testimonio de esta forma ni, anteriores al presente, de zanja. Por otra parte, dada la incierta etimología de zanja, merece ser tenida en cuenta la variante anja, aunque parece muy probable que se deba simplemente a una falsa separación del artículo: las (s)anjas. Lo cual, a su vez, sería indicio de que se trataba de una palabra poco corriente.

\section{apañar}

'Tomar', 'apoderarse'. Salidos de la peste y la cizaña / que den- 
CONTRIBUCIÓN AL VOCABULARIO ESPAÑOL DEL SIGLO XVI

tro en Santander se ban escapado / y do a Pero Meléndez ésta apaña, II, III, 30.

\section{apastado}

'Apacentado'. Toros en selbas apastados, I, I, 43.

\section{apocar}

'Disminuir'. Se ban baziendo cosas que nuestra bacienda así se apoca, $43 r$.

\section{argüido}

'Alegato'. $Y$ sin ruegos oir ni su argüido, II, I, 103.

No he encontrado ningún testimonio de esta palabra.

\section{arrequives}

'Ribete', 'guarnición'. De carmesí vordada, que allegaba / con oro, con requibes recamados, III, III, 37.

\section{arriscarse}

'Arriesgarse'. Pero ninguno puede aqui escusarse / que no pudo estorbar este gran daño, I que pudiera muy bien sin arriscarse, I, III, 83.

\section{arubinar}

'Arruinar'. Arubinar entonces [...] por el rescate puro y gran dinero, 492r. Desde entonces siempre ba procurado arubinar aquella nombradía, $493 v$.

No he encontrado ningún testimonio de esta palabra, que hay que vincular con salmantino arrubinar 'derrumbar', 'tirar', 'caer' (J. Lamano, El dialecto vulgar salmantino. Salamanca,
1915, s.v.); cat. rovina, ruvina 'riada'; it. rovinare 'caer' 'arruinarse'.

\section{asadura}

'Hígado'. Las tripas y asadura le sacaron, III, III, 106.

\section{asina}

'Así'. Barracelio, que asina se nombraba, I, VII, 78.

Pocos años después merecía este juicio desfavorable: Evita voces vulgares $[\ldots]$ como $[\ldots]$ asina (P. Espinosa, El perro $y$ la calentura, en Obras. Ed. de F. Rodríguez Marín. Madrid, 1909, 194). Documentación de esta forma, en A. M. Espinosa, Estudios sobre el español de Nuevo Méjico. Buenos Aires, 1930, I, 77-9.

\section{atraillar}

'Sujetar', 'enlazar'. Se bizo un secto en forma de estacada / que atraylla con muy fuertes maderos, II, IX, 57.

\section{azores}

'Muro', 'muralla'. Artillería / plantó sobre una puente en los açores, III, VII, 21.

No conozco otro testimonio que azor, en el Fuero de Madrid (IX, XIV y XCVIII).

\section{bala}

'Proyectil'. Le ba faltado / valas y munisción con lo pasado, III, V, 93. En cinco días continuos se gastaron / las valas que tenía toda la armada, III, $\mathrm{V}, 119$. 


\section{F. González Ollé}

Es italianismo, ausente de Terlingen, que no encuentro antes de Pimentel.

\section{balazo}

'Golpe de bala disparada'. Por mil partes rompieron a pedazos lel galeón San Matbeo con balazos, III, V, 106.

\section{balde}

'Cubo para transportar agua'. Valdes de todas suertes para las aguadas, 648r.

La primera documentación que cita Corominas es de 1587 (D. García de Palacio, Instrucción náutica).

\section{balde, de}

'Gratis'. Darlos de balde a aquel que los quisiere, I, I, 66. $Y$ de valde les dieron la comida, II, I, 81 .

\section{baque}

'Golpe'. El audictor, con cólera de daque, I da con el más gallardo luego un baque, II, I, 104.

\section{basilisco}

'Pieza de artillería de determida especie'. Sacres y basiliscos, Piezas finas, II, LV, 27. Disparaban de veras a porfía / un basilisco $y$ otro de repente, II, $\mathrm{XI}, 3$.

\section{batidero}

'Lugar donde baten las olas'. $E l$ francés acomodando / se estaba dentro un dique a un batidero / de la mar, III, III, 54. belicoso

'Inclinado a la guerra'. El belicoso / Conde de Fuentes, III, VII, 83.

\section{berberrear}

Cfr. verberrear.

\section{bestiamen}

'Conjunto de bestias'. Tiene esta tierra bestiamen tanta / qual son bacas y bueyes, I, I, 41.

No figura en Terlingen. Carominas cita la forma bestiame como italianismo.

\section{bestión}

'Bastión, cierto género de fortificación'. Pone contra Mons nuebos bestiones, II, III, 27. Italianismo estudiado por Terlingen (213-4).

\section{boca negra}

¿'A bocajarro'?, ¿'a quemarropa'? Apuntó a boca negra, y no fue a tiro, I porque le sacudió de en medio en medio / al capitán un golpe sin remedio, III, II, 70 .

\section{bocarón}

'Abertura', 'brecha'. Los tablones / tapan del río aquellos bocarones, I, VIII, 28.

\section{braca}

¿'Rama'? Y bracas de los árbores no halladas, III, IV, 60.

El contexto y la proximidad fonética con cat. branca, fr. branche, etc., hacen suponer que tenga el mismo significado que estas palabras. 


\section{bravoso}

'Bravo'. Por ser su potestad brabosa y fiera, I, I, 34. Capitanes brabosos y excelentes, I, VIII, 43.

\section{brazo partido, a}

'Sin usar armas'. Ni consiente / la armada inglesa bazer braço partido / si no es acañonearse, III, V, 68.

El significado consignado es el que figura en el Dicc. Aut., mantenido hasta el actual Dicc. Acad., mientras que para Covarrubias es 'proceder igualmente, sin ventaja de uno a otro'.

Pero el contexto hace pensar en 'cuerpo a cuerpo'.

\section{brindar}

'Manifestar, al ir a beber, el bien que se desea'. Conbidoles I a una muy rica cena, y ban brindando / $y$ brindan todos estos conbidados, I, II, 20.

\section{brindes}

'Brindis'. Todos comen cubiertos juntamente / y el Rey Enrico un brindes alli ba becbo / a la salud del Rey, III, VIII, 77. No he visto documentada esta forma. También emplea Pimentel las variantes que se consignan a continuación.

\section{brindez}

'Brindis'. Que al de Orange ba de bazer un brindez solo, / el qual suene de un polo al otro polo, III, II, 12.

Es la forma que recoge Cova- rrubias y la usada por Cervantes, Viaje del Parnaso, III, 376.

\section{brindiz}

'Brindis'. Al Conde de Egmont le brindan luego, / dizen: Brindiz a vos, muy poderoso, I, II, 24.

El contexto denuncia el origen verbal de este sustantivo.

\section{cabe}

'Golpe de bola, en algunos juegos'. Juego que era, qual suelen en los trocos, I darse un cabe una vez, II, XII, 53.

No encuentro testimonios literarios anteriores, sí posteriores, como éste, muy claro, de $\mathrm{A}$. Zamora (Entremés para la fiesta de Todo lo vence el amor. Madrid, 1709, 30): Se dio un cabe, golpe en bola.

\section{cabizcaído}

'Cabizbajo'. Andaban todos ya cabiscaydos / sin ánimo de verse reparados, III, VI, 95.

\section{calabozo}

'Aposento de cárcel'. Un suzio calabozo, III, III, 99.

\section{calva}

'Engaño'. Descuibrele una calba I el Duque allí al de Orange, y su dislate, / que le calbó quitando de una entrada / al Príncipe dos mil desa llegada, II, III, 36.

\section{calvar}

'Engañar'. Porque en las ocasiones Marte calba / al que de los 


\section{F. GonzÁlez Ollé}

descuydos más se fía, II, I, 49. Cfr. calva.

Figura este verbo en varios diccionarios del siglo XVII, pero no lo he encontrado en textos. Lat. c a l u o r 'engañar'.

\section{calvino}

'Calvinista'. La calbina secta, I, III, 44. Calbinos, luteranos, I, IV, 14. Este templo calbino, I, IV, 21.

\section{camarada}

'Grupo de soldados'. De nuestro tercio fue una camarada / de asta doze, buscando su ventura, III, IV, 7. Partidos / éstos, quedan tres mill de camarada, / media legua metidos de embosca$d a$, III, VIII, 57.

\section{camino carretero}

'El que está expedito para el tránsito de coches'. Este fue el camino carretero, I, III, 1.

\section{canivete}

'Cuchillo pequeño'. Tan fuertes [petos] que no basta un pistolete / pasarlos, quanto más un canibete, III, VI, 50.

$\mathrm{El}$ autor, poco antes, llama $\mathrm{Cu}$ chillejo al mismo instrumento.

\section{cañonazo}

'Disparo de cañón'. Al enemigo aparta a cañonazos, III, V, 100.

\section{carretero}

Cfr. camino carretero.

\section{casar}

'Conjunto de casas que no forman pueblo'. Un casar donde entonces asistía / gran número de gente allí alojada, II, XIII, 51 .

\section{casero}

'Lo que se hace, se cría o se tiene en casa y no se compra fuera: como el lienzo, el pan' (Dicc. Aut.). De pan y bastimentos quál se bían / que aun para quinze días no ay enteros / destos mantenimientos tan caseros, III, VI, 94.

\section{casina}

'Casa de campo, utilizada con fines bélicos'. La gente en las casinas se alojaba / y guarda conbeniente se ponia, III, II, 108. Estos en las casinas retirados / estaban, que la nocbe cayó obscura, III, III, 60.

No conozco testimonios anteriores de esta palabra, probable adaptación del fr. cassine, que a su vez procede del piam. cassina.

\section{cestones}

'Cesto grande $[\ldots]$ que relleno de tierra sirve en fortificaciones y trabajos de sitio para cubrirse con rapidez, y también para revestimiento'. Invenciones de guerra y de cestones, II, III, 27.

Tomo la definición de Almirante, que aduce varios testimonios de historiadores y tratadistas militares (Palafox, Coloma, Sandoval, Mendoza y otros).

\section{clarín}

'Instrumento musical semejante a la trompeta, pero más peque- 
ño y de sonidos más agudos'. $E l$ clarín por su orden declaraba / ser español el zumbo, II, XI, 4. $Y$ los nuestros clarines les pidiendo / batalla, pero nadie se atrevía, II, XIII, 60.

\section{comarcano}

'Cercano'. Las villas comarcanas / de París, III, VII, 41.

\section{comunt}

1. 'Conjunto de habitantes de un lugar'. El pópulo y comunt no está indignado, I, II, 32. El comunt todo se desmande, I, II, 58. Hizo a todo el comunt del parissiano / le salga a rescibir, III, III, 82 .

2. 'Lo que pertenece a la generalidad'. El bien comunt, I, II, 57. Para tratar el bien comunt, I, VII, 85.

3. 'De clase inferior'. De la gente comunt $y$ bulgo entero, I, I, 73.

Resulta extraña la presencia, constante, de - $t$ final. Quizá se deba a contaminación de algunos adjetivos que, en la escritura, presentaban a veces -nt (grant, sant, etc.). En todo caso, esta peculiaridad muestra la escasa difusión que aún conocía esta palabra, poco frecuente en los textos medievales.

Pimentel usa también el adverbio comuntment, I, I, 86.

\section{conjetura}

¿'Disfraz'?, ¿'persona disfrazada'? Mas, si quieren ver másca- ras orrendas / y conjeturas vellas y graciosas / que suelen celebrar carnestolendas, $241 r$.

\section{conventículo}

'Reunión clandestina'. Cada cual conventículo bazía, I, IV, 6.

\section{cosa}

'Nada'. Una bez y otras mill le ba diziendo / que venga a la vatalla, mas es tanta / del francés su crescida cobardia, I que cosa a la vatalla respondía, III, VII, 22.

Resulta raro ya, en la época de Pimentel, que cosa, con sentido negativo, figure en frases que no sean negativas.

\section{coyuntura}

'Oportunidad'. Ni de verse tuvieron coyuntura, $180 v$.

\section{culebrina}

'Pieza de artillería de determinada especie'. Con piezas dies y seis son culebrinas, III, VIII, 35.

\section{cundir}

'Afectar', 'infectar'. Mas tanto aqueste daño en si ba crescido / que todo el País Vaxo obo cundido, I, I, 7. El daño así cresciendo, I al universo todo amenazando, / iba de unos en otros tan cundiendo, I, IV, 57. Como en sus primeros testimonios, presenta en los consignados el rasgo característico de aplicarse a la propagación de males. 


\section{F. González Ollé}

\section{charrúa}

'Barcaza', 'pontón'. $Y$ donde estos [árboles] faltaron por la bondura / profunda, con charrúas anchoradas / y otros vaxe les suplen la rutura, III, IV, 60 .

\section{chichota}

Cfr. xixota.

\section{chismero}

'Chismoso'. Llamándole traydor y que sirbia / de solo ser chismero, I, II, 27.

\section{daimusela}

'Muchacha'. Las daymuselas le becban maldiciones, / los muchachos con vozes acudieron, III, III, 94.

\section{daque}

¿'Don'?, ¿'regalo'? El audictor, con cólera de daque, I da con el más gallardo luego un baque, II, I, 104.

Un contexto más amplio que el trascrito permite comprender con seguridad el pasaje copiado: 'el auditor, sin más que oir una denuncia, manda degollar al soldado'.

Al significado propuesto para daque llego gracias a este testimonio de J. de Pineda, Agricul. tura cristiana (XXV, XXXV), el único que me es conocido: P.Yo os prometo de no me sentar a la mesa sin que [...] os envie un buen daque. F.- Yo deseo ver el toma. No suscitará ninguna duda que a este último texto conviene justamente el significado propuesto. Daque se ha formado, en mi opinión, so- bre *dacar (hipotético infinitivo del frecuentísimo daca) como sustantivo verbal, categoría a la que pertenece su antónimo toma en la réplica.

En el texto de Pimentel, daque, complemento de cólera, equivaldría a 'gratuita' o, mejor, 'de dar (castigo)'.

\section{democrático}

'Relativo a la democracia o gobierno popular'. Es provincia, mas, como da en sus cosas, i a bibirse debaxo de un estado / democrático en vías anchurosas. II, XV, 489r.

\section{dentellada}

'Acción de morder con ansia' Daban dentelladas / en el pan y la carne que alli babia, II, IV. 40.

\section{desbarato}

'Desconcierto', 'derrota'. Es ruvna universal $y$ desbarato, I, IV, $86 r$.

\section{desmanar}

'Deshacer', 'impedir'. Mas todos en vano trabaxaron, I que el biento se bolbió, y éste desmana / el intento que todos pretendian, III, V, 63.

\section{desvainada}

'Desenvainada'. Con navaja desvaynada, II, XV, 2.

\section{desván}

'Desmán'. Y la caballería en los desvanes / de la villa también se balló presente, II, XIII, 78. 
CONTRIBUCión al VOCABUlario ESPAÑol DEL SIGLO XVI

\section{devantar}

'Reclutar'. Iban a debantar gente $y$ pendones, I, VI, 30.

\section{dique}

'Muro de contención de agua'. Está en un dique o paso, II, IV, 27. Digo que Flandes liene en su llaneza / ciertos diques de quien es defendido / del creciente mar, II, IV, 31. Un dique es como puerta o fortaleza I que, si queréis abrirle, es anegado / el pueblo, II, IV, 31. Cfr. empantanado.

El testimonio de Pimentel viene a ratificar la opinión de Corominas (para el siglo XVI cita un vocabulario de 1585 ) de que pudo tomarse directamente del neerlandés, por coincidir su aparición en castellano con las guerras de Flandes.

\section{disforme}

'Desproporcionado por su gran tamaño'. En su mano un disforme $y$ gran pescado, III, I, 33.

\section{empantanado}

'Cubierto o lleno de agua'. Aquella tierra e isla empantanada / estaba y cortaduras que tenía / del agua, III, IV, 39. Por traición, sin pensar, todos se vieron / por agua de un gran dique empantanados, III, IV, 83.

\section{encamisada}

'Sorpresa bélica nocturna'. De noche se le dio una encamisada I que perdió más de mil en un memento, II, III, 41.

\section{enclusa}

'Esclusa'. Por un raso / estanque de agua lleno y mil enclusas, II, VII, 19. El Dicc. Aut. da primacía a esclusa, considerado galicismo, sobre enclusa y no cita ningún testimonio de esta última palabra; tampoco yo lo he encontrado.

Corominas documenta esclusa en los historiadores de las guerras de Flandes (Mendoza y Coloma) y ratifica el origen francés, ahora de nuevo confirmado.

\section{enriedo}

'Maquinación', 'enredo'. Imaginando enriedos, daños, males, I, II, 60 .

\section{entremés}

'Alboroto'. Vio motines entre ellos $y$ entremeses, III, III, 10. El consignado o uno muy próximo es el significado que tiene en: Por no pagarme haces agora esos entremeses (L. de Rueda, Armelina. Ed. de F. González Ollé. Salamanca, 1967, 125); otros testimonios de entremés, con significados próximos al presente ('engaño', 'locura', etc.) y no con el de 'género dramático', pueden verse en W. S. Jack, The early entremés in Spain. Filadelfia, 1923, 21-4.

\section{esmeril}

'Pieza de artillería de determinada especie'. Y en lugar de jugar los esmeriles, / resuenen las trompetas $y$ añafiles, II, XI, 7. 


\section{F. González Ollé}

Tan solo un esmeril o culebrina I de repente dio berida tan malina, II, VI, 29.

\section{estanque}

'Depósito artificial de agua'. Estanque de agua lleno y mil enclusas, II, VII, 19.

\section{estaño}

'Estanque'. Si el estaño / de un grande foso de agua no estorbara / que asalto no se diese, II, VII, 23.

No cree Corominas que haya sido voz castiza en castellano, aunque la empleara Aldrete, seguramente por latinismo, del cual pasó al Dicc. Aut. Pienso que pudo ser mayor la difusión de dicho vocablo, a la vista de este testimonio y de otro que aporto: Torre que estaba en mitad del estaño (Quijote, I, XXXIX).

\section{esterlin}

'Escocés'. Ytalianos, franceses y gascones, / ingleses y exterlines, I, V, 65 .

\section{estoperol}

'Especie de mecha'. Estoperoles para en caso de que [...] el artillería baga algún daño en los nabios, 648r.

\section{estufa}

'Género de braserillo' (Covarrubias). De estufas $y$ de fuegos por doquiera, I, I, 34.

\section{favorido}

'Favorecido'. A la gran goberna- dora / Madama Margarita ba favorido / y la respeta como a superiora, I, II, 29. Y el de Alesón, de berejes faborido, III, VI, 10.

\section{finanzas}

'Hacienda pública'. El tercer consejo es de finanças, I, I, 79. No encuentro testimonios anteriores al presente. Cfr. nota 3, final.

\section{finiesta}

'Ventana'. Las finiestas o ventanas, $182 r$.

La terminación de esta palabra, garantizada por la rima con puestas e inbiestas, resulta excepcional frente a -tra, etimológica, que presentan los testimonios conocidos.

\section{flámula}

'Especie de grímpola'. Banderas $y$ flámulas, $648 r$.

\section{flema}

'Paciencia', 'lentitud'. $Y$ en todas las cosas tienen flema $y$ brios / para durar en ellas no alteradas, I, I, 57.

\section{formaje}

'Queso'. Por la mucha leche que ay sobrado, / [...] el formaxe es muy preciado, I, I, 44.

\section{franciscano}

'Francés'. Enrique de Balois, Rey franciscano, III, VI, 20.

\section{frenil}

No he encontrado ningún testi- 
CONTRIBUCIÓN AL VOCABULARIO ESPAÑOL DEL SIGLO XVI

monio de este vocablo, que figura como miembro, sin ninguna determinación, de una enumeración de objetos náuticos: freniles, valdes de todas suertes para las aguadas, 648r. Ensayo una explicación: En el vocabulario con que $\mathrm{D}$. García de $\mathrm{Pa}$ lacio cierra su Instrucción náutica para navegar (México, 1587) aparece: Fonil es con que envasan el agua y vino en la pipa, es decir, 'embudo'; no hay remisión al texto, en el que se encuentra, en forma diversa, un funil de cobre $y$ otro de palo $(110 v)$. En el Dicc. Aut. es fonil la única forma representada. Por su proximidad textual a baldes, pienso que frenil puede ser 'embudo', es decir, identificarse con fonil. Esta presunta forma aberrante, frenil, quizá se deba a un cruce con frenel 'calabrote', explicable en un profano en materia náutica, como puede suponerse a Pimentel.

\section{fretir}

'Freir'. El qual obo fretido / en manteca de puerco [...] y fretido guardó, III, VI, 46.

Fretir está atestiguado en diversos ámbitos rurales de la Península, pero no conozco documentación antigua. El testimonio presente confirma la suposición de Corominas sobre la antigüedad de este vocablo, deducida por él de la presencia de fretidera, fritiendo, junto a freir, en Alonso de Palencia. frisa

'Tela ordinaria de lana'. Y un cadabalso alto se endereza / todo de frisa negra conveniente, I, VII, 52.

\section{funeroso}

'Fúnebre'. Los atambores son muy funeroso / bazen, II, XIII, 79.

\section{ganapán}

'Los que ganan su vida y el pan que comen a llevar a cuestas y sobre sus hombros las cargas' (Covarrubias). Muchachos ganapanes, I, III, 87.

\section{ganapanil}

'Referente al ganapán o propio de él'. Gente ganapanil, ya paresciendo, / limosnaban de puerta en otra puerta, I, II, 61.

\section{gastador}

'Soldado que se aplica a abrir trincheras y a otros trabajos semejantes'. Para ponerle [al puente] en orden, / ba estrechado al inbentor, soldados, gastadores, / que todos son en él trabajadores, II, VII, 30.

Almirante cita varias autoridades, posteriores a Pimentel, coincidentes en ser cronistas de Flandes (Coloma, Avila, Mendoza, Barén).

\section{grandor}

'Tamaño'. Una copa de oro entera / de buen grandor, III, II, 10. 


\section{F. GonzÁlez Ollé}

\section{guzmán}

'Noble que servía como soldado'. Tres capitanes / traen con bandera escuadras $y$ guzmanes, I, VI, 59.

\section{halaguero}

'Agradable'. De un prado al parecer verde alaguero, II, VII, 27.

\section{hemisferio}

'Mundo'. El hemisferio en este tiempo ba dado / una muestra jamás vista ni oyda, III, VI, 3.

\section{humilladero}

'Capilla de un templo'. En cada templo estaba fabricado / un rico humilladero bien labrado, I, $\mathrm{V}, 9$.

Lo normal es que bumilladero designe una construcción exenta.

\section{inhabitable}

'No habitable'. Tierra inhabitable, I, I, 12.

\section{inimicicia}

'Enemitad'. Sembrando inimicicias, $85 v$.

\section{inobediencia}

'Desobediencia'. Quántos males en el mundo ba becbo / la innobediencia, I, III, 1.

\section{invencionero}

'Falsario', 'mentiroso'. Que buscaba de ser invencionero / para dar los martirios con su mano, I no contento con darles cruda muerte, II, II, 11.
Covarrubias, 'forjador de mentiras'.

\section{jarife}

'Jerife, dignidad árabe'. Del Rey Don Sebastián y los partidos que le bizo el jarife, 486v. El jarife le dio muy mal fundado, siendo africano pérfido, ibid.

\section{lacrimosa}

'Llorosa'. Bolbióse toda Francia lachrimosa, III, VI, 32.

\section{ladero}

'Lateral', 'situado al lado'. Un trompeta mató que está ladero / del Duque, III, II, 93.

\section{largas}

'Demora'. Visto el Señor Don Juan que aquellas largas / son para bacer más daños cada día, II, XII, 17.

\section{latrina}

'Letrina'. A un suzio calabozo, semejante / a una latrina, III, III, 99.

\section{leyente}

'Lector'. Para que entiendan esto los leyentes, I, I, 70 .

\section{libelo}

'Injuria'. Libelos $y$ denuestos le echaban, I, II, 27. Libelos por las calles $y$ en audiencias / dicen, escriben, fijan y cantaban, II, XI, 66.

\section{limosnar}

'Pedir limosna'. Gente ganapanil, ya paresciendo, / limosnaban de puerta en otra puerta, I, II, 61.

En diccionarios de los siglos 
CONTRIBUCión AL VOCABULARIO ESPAÑOL DEL SIGLO XVI

XVI y XVII encuentro limos$n(e) a r$ 'dar limosna', pero no hallo testimonios del significado presente.

\section{lite}

'Pleito'. Apenas esta lite fue acabada, II, I, 15.

\section{lodazal}

'Paraje cubierto de lodo'. Por los lodazales y la arcilla / que a veces los llegaban a la rodilla. II, IX, 38 .

\section{lutero}

'Luterano'. Agora sea [doctrina] lutera o calbina, I, IV, 17. Salió el lutero bando muy potente, II, VI, 37. Pueblo de luteros guerreros, III, VII, 47.

\section{luto}

'Paño negro'. Pues muerto el de Egmont como lo cuento, / su cuerpo con un luto le cubrieron, $180 r$.

\section{manada}

'Grupo de personas'. La muchedumbre mal experimentada I cargó sobre los pocos que se vían / [...]. Luego alli se retrajo esta manada, II, X, 42. Agora entra de presto una manada, / aora diez, abora ciento, II, X, 71. Con grande pieza / de otros gentileshombres en manada, II, XII, 50.

\section{manida}

1. 'Vivienda', 'habitación'. Antes en su baxel fue su manida, III, V, 109.
2. 'Reunión', 'grupo'. Hazen corrillos, juntas y manidas, I, II, 50.

\section{manta}

'Palabrota'. Blasfeman y echan crudas mantas, I, VII, 35.

Salí fuera como un loco, echando mantas y no de lana (M. Alemán, Guzmán de Alfarache, I, II, VIII).

\section{marmalla}

'Morralla, grupo de gente despreciable'. Y sale de los gueus una canalla, I tan rotos de vestido ni calzado, / que no sé do fue junta tal marmalla, I, III, 52.

Cfr. murralla.

\section{martinista}

'Luterano'. Se arrimaron / a su Martín Lutero y martinistas / por tener esta secta se llamaron, I, IV, 7. Martinistas se juntan de otro bando / contra los calbinos litigando, I, V, 66. Un bereje martinista, II, XIII, 28.

\section{mochila}

Cfr. mucbila.

\section{momo}

'Mofa'. Házenle burlas, momos por do pasa, I, II, 27.

\section{mordaza}

'Instrumento que se pone en la boca para impedir el habla'. Una mordaza por la boca entera, III, III, 99.

morralla

Cfr. murralla. 


\section{F. GonzÁlez Ollé}

motilado

'Cortado', 'recortado'. Barbas a la francesa motiladas, III, VIII, 56.

\section{motín}

'Alteración de soldados y gente de guerra' (Covarrubias). Vio motines entre ellos y entremeses, III, III, 10.

\section{muchila}

'Morral de soldado'. Sacos y muchilas de angeo, 648r.

\section{murmureo}

'Murmuración'. Sembrando un murmureo muy malbado / y una fama en las plaças, I, II, 49.

\section{murralla}

'Grupo de gente de escaso valor'. Siempre el Duque de Alba ba procurado / de no poner a riesgo una murralla / de gente, con que en Flandes fue venido, II, III, 38.

A juzgar por el contexto, la connotación peyorativa de esta palabra debe de ser más atenuada que la de marmalla (cfr.).

\section{nocente}

'Dañoso'. Alguna gente / a su servicio, nada convenible, I ba derramado fama tan noscente, I, V, $109 v$.

\section{paisano}

'Del país'. Dos de españoles, dos son italianos, / tres tropas de caballos payzanos, III, VIII, 23. Estos quarenta viste de villa- nos $[\ldots]$ al uso de la tierra paysanos, III, VIII, 56.

\section{paniguado}

'Servidor', 'allegado'. Baltasar, borgoñón, que es un criado / del Príncipe de Orange paniguado, III, III, 87.

No puede asegurarse que mantenga el significado etimológico ('servidor que recibe el alimento de su amo'), pero sí conserva el significante originario

\section{pantanoso}

'Propio del terreno donde abundan charcas y cenegales'. Aunque toda esta tierra buimida sea, I por ser llana y con ríos, pantanosa, I, I, 30.

\section{papo lleno, a}

'A boca llena', 'abiertamente'. Luego lo loa el bulgo a papo lleno, I, II, 34.

\section{paquete}

'Conjunto unido, mazo de papeles'. $Y$ si cartas o abisos escribia, / son coxidos de presto en apretura, / como muchos paquetes disfraçados, II, XIV, 49. Tiene interés este testimonio, el más antiguo que conozco de paquete, porque esta palabra se considera galicismo, pero en última instancia remonta a neerl. packe.

\section{parisiano}

'Parisino'. Hizo a todo el comunt del parissiano / le salga a rescibir, III, III, 82. 
CONTRIBUCióN AL VOCABULARIO ESPAÑOL DEL SIGLO XVI

\section{parlamento}

'Asamblea'. Y llegado a palascio con contento, / le ban llebado a la bora al parlamento, III, VII, 25. Enternescióse todo el parlamento, III, VII, 33.

\section{particulado}

'Particular'. General y lo más particulado, II, XII, 44.

\section{pelea}

'Afán'. Si los naturales con pelea / no probasen con sobra aquella bermosa / fruta que el gran Nobé plantó, I, I, 30.

El Dicc. Aut. recoge esta acepción, sin documentarla.

\section{pelotolas}

'Proyectil esférico'. Sacres que al cielo dan bolatería / con pelotolas de fuego, II, III, 27.

No conozco ningún otro testimonio de esta palabra.

\section{peñosa}

'Pesada', 'abrumadora'. Diré otra cosa / muy digna de sentir $y$ bien peñosa, II, VI, 31 .

\section{perdidoso}

'El que pierde'. Hasta que perdidoso $y$ sin ganancia $[\ldots]$ se bolbió en Francia, III, VI, 12. El Duque de Namur en Dreus ba buido / y el Duque de Humena, perdidoso, / en Nantes se metió, III, VI, 90.

\section{persiano}

'Persa'. Turcos $y$ persianos, III, VI, 4.

\section{petrera}

'Aprieto', 'dificultad'. Quiso Dios, pues, estando en tal petre$\mathrm{ra}$, I que el biento fue alguin tanto mejorado / y por eso siguieron la carrera, III, V, 117. Es difícil admitir que esta palabra conserve la estructura silábica originaria de su familia léxica ("apetrar); más fácil es creer que la coincidencia es secundaria, por una nueva metátesis, quizá ocasional, "pretera $>$ petrera, pero de ninguna de estas formas (ni de sus respectivas variantes con $a$ - inicial) encuentro testimonios. Cierto que petrera figura en el Dicc. Aut. como 'riña con piedras', pero me inclino a considerarlo homónimo.

\section{pillaje}

'Saqueo'. Los nuestros dieron forma en el pillaje, / ques dicho saco mano en buen lenguaje, III, VIII, 61.

Queda claro que Pimentel tenía conciencia de la novedad de esta voz, que no se generaliza hasta el siglo siguiente.

\section{pipa}

'Barril'. Pipas de cerbeça, III, VIII, 51.

\section{pique, a}

'A punto (de)'. Estuvo a pique dar un gran castigo [...]. Mas un frayre [...] lo alcanzó [el perdón] de merced, III, II, 76. Estando a pique de partirse, II, III, 41. Todas están al pique aparejadas, III, V, 3. 


\section{F. GonzÁlez Ollé}

\section{pistolete}

'Pistola corta'. Armas y pistoletes $y$ paveses, II, IX, 60 .

Anticipa la fecha de aparición.

\section{plano a plano, de}

'Enteramente', 'totalmente'. Todo lo escribí de plano a plano, III, VI, 13.

\section{plataforma}

'Superficie horizontal elevada sobre el suelo'. Luego los españoles lebantaron / una gran plataforma de alto estado [...] y puesta en perfición allí ban plantado / pieças de artillería, II, XIV, 80.

Corominas documenta esta palabra en 1595 y rechaza su condición de italianismo por la de galicismo, lo que parece muy acertado.

\section{plomada de hondura}

'Sonda marina'. La plomada de hondura mesuraba, III, V, 115.

\section{polonés}

'Polaco'. Poloneses y alemanes, III, VI, 4.

\section{polvorín}

'Compartimiento del barco donde se guarda la pólvora'. Llevó su capitana aquel castigo / del polvorín terrible, III, V, 79 .

\section{pópulo}

'Pueblo'. El pópulo y comunt no está indignado, I, II, 32. El pópulo furioso todo entero, I, II, 47. El pópulo y ciudad se perdería, I, III, 33. Fueron estas demandas a que viese I la firmeza que el pópulo tuviese, III, VII, 12.

Resulta extraña la presencia, reiterada, de esta forma culta, que no encuentro en diccionarios ni en textos. Quizá sea debida a adaptación de it. pòpolo o a una regresión de populoso (cfr.), adjetivo que Pimentel prodiga y que no he visto documentado antes de él.

\section{populoso}

'Abundante en población'. Esta ciudad grande $y$ populosa, I, IV, 41. Es Boldrique, ciudad muy populosa, I, V, 8. La populosa / gran villa de Leni, III, VII, 39. Las villas comarcanas / de París, que abia muchas populosas, III, VII, 41. Es, pues, Roan ciudad muy populosa, III, VII, 68.

\section{portar}

'Llegar a puerto'. Sancho de Avila ba llegado / con bajeles por mar $y$ allí ba portado, II, IX, 44.

Aportar, con el mismo significado, debe de ser más frecuente: El soldán aportó al puerto (Crónica General, cap. 947).

\section{proviso}

'Instante'. Vino un mos. de Lumel en un proviso, II, II, 23. $A$ este da abiso / de juntarse con él en un probiso, II, VIII, 27. Lo qual él pudo bacer en un probiso, II, VIII, 35. No púdose tan presto que no biziesen / los de dentro venir en 
CONTRIBUCIÓN AL VOCABUlario ESPAÑOL DEL SIGLO XVI

un probiso / a quatro mill villanos, II, XIV, 50.

También aparece como adverbio: Un fuerte se bizo / por guarda de la villa abentaxado I con presteza y se puso en él probiso / guarnición, III, IV, 96.

\section{pujante}

'Poderoso'. La Musa, río pujante, III, VII, 81. Rey de Francia le nombren muy pujante, III, VII, 89.

\section{ralea}

'Clase', 'especie'. Fructas muy dibersas en raleas, I, I, 22. Diversas en lenguajes $y$ raleas, $\mathrm{I}$, I, 29.

\section{raso, a lo}

'Llanamente', 'abiertamente'. El Principe de Orange allí a lo raso / dice que el Duque de Alba los poderes / luego les quitará, I, VI, 27.

\section{recuesto}

'Paraje en declive'. Los nuestros doze súbense a un recuesto, III, II, 69. Do no ay valles ni recuesto / sino todas campañas anchurosas, I, I, 24.

\section{refulgente}

'Que emite resplandor'. El sol más preclaro y refulgente, II, VII, 69.

\section{reistre}

'Soldado alemán de caballería'. El Príncipe de Parma en el presente / seis mil reystres juntó en caballeria, II, XIV, 4. Que era general a este inmediato / de reystres $y$ demás caballeria, III, II, 104. Y más ganaron dos estandartes de reystres que era su caballeria, III, III, 56. También, en II, XIV, 12, 14, 15, 21, 24, 29, 39.

Almirante registra reitre (y apunta correctamente el étimo, alemán Riter 'jinete') como 'soldado alemán y mercenario de caballería', en oposición a lansquenete 'soldado alemán y mercenario de infantería'. Corominas recoge la misma forma reitre, que encuentra en el diccionario de Terreros; supone que se introdujo en castellano a través del francés, donde se documenta en el siglo XVI.

A falta de información sobre si procede directamente del neerlandés, la forma reistre, de $\mathrm{Pi}$ mentel, con $-s-$, viene en apoyo de la suposición de Corominas, pues los testimonios antiguos franceses (al menos los recogidos en el FEW) presentan idéntica estructura silábica.

\section{requibes}

Cfr. arrequives.

\section{reservado}

'Eximido', 'excluido'. Ni queda Inglaterra reserbada / de Flandes el incendio de abadías, I, I, 2. No se ballan animales venenosos / en esta tierra y de ello es reservada, I, II, 38 .

\section{retroguarda}

Cfr. retroguardia. 


\section{F. González Ollé}

\section{retroguardia}

'Retaguardia'. $L a$ retroguardia, que es cuerpo postrero, III, V, 45.

Corominas documenta esta palabra en Juan de Castellanos (1590). Pimentel, que usa también retroguarda (III, V, 55), denuncia, implícitamente, como se ve, la novedad de retroguardia.

\section{revellín}

'Obra exterior que cubre la cortina de un fuerte y la defiende'. Era este rebellín sobre una puerta / de la ciudad de Harlem, II, VI, 10. Delante de esta puerta fabricado / estaba un rebellín atrincheado, II, XIV, 81.

Los primeros testimonios conocidos son contemporáneos del presente.

\section{rondón, de}

'Impetuosamente'. De rondón entraron, I, II, 64. Entraron de rondón, como un gran río / que, enojado $y$ con furia, derribando / va puentes, casas, torres, II, II, 70.

\section{sacre}

'Pieza de artillería de determinada especie'. Gran salba / de cañones $y$ sacres a remate, II, III, 36.

Cfr. pelotolas.

\section{satrapa}

'Prendero', 'empeñero'. El berreruelo ba de ir cas del judio. I Y porque desto nadie no se escapa, / yo pongo por testigo dello al mío / y también a mis calzas y mi capa, / que tienen mucbos callos de costumbre / de estarse siempre en casa del satrapa, II, II, $240 r$.

El significado propuesto deriva de la segunda acepción que consigna Covarrubias: $A l$ que es gran bullidor de negocios solemos decir que es un sátrapa. También el Dicc. Aut. ofrece un significado próximo: 'el ladino y que sabe gobernarse con astucia e inteligencia en el comercio humano'. El testimonio de este diccionario, Manuel de León, pide que sátrapa sea palabra esdrújula; en Pimentel, rima y metro exigen que sea llana.

\section{secretar}

'Secuestrar', 'confiscar'. Les restituyen, fuera de esto, / sus bonras $y$ baciendas secretadas, II, IX, 11.

La forma secretar parece etimología popular de secrestar, que encuentro en Mena, Laberinto, 2389: el largo trabajo secresta la mente, y figura en Covarrubias como 'poner una cosa en depósito'.

\section{sisa}

'Impuesto'. Grande sisa / sacó mucho tesoro, II, XIII, 30.

\section{sitiado}

'Situado', 'asentado'. [Ginebra] en el fin de Saboya está sitiada, I, III, 19.

Coincide con el cat. sitiar '(a)sentar' y tiene interés para justificar la -j-de sitio. 


\section{CONTRIBUCIÓN AL VOCABULARIO ESPAÑOL DEL SIGLO XVI}

\section{sobrehueso}

'Al que nos es muy importuno decimos sernos gran sobrehueso' (Covarrubias). Tendrá dos sobrehuesos desiguales / que serán un alférez y un sargento, II, II, 237.

\section{soez}

'Indigno', 'vil'. Van de un ábito baxo, suez, sencillo, II, II, 60 .

\section{solevantar}

'Sublevar'. Los pueblos se solebantaron, I, VII, 73.

\section{soñoliento}

'Acometido del sueño'. Está nuestra gente soñolienta, III, II, 81.

\section{sorda, a la}

'Silenciosamente'. Caminando a la sorda, III, II, 79.

\section{sublimado}

'Sublime', 'ensalzado'. $Y$ los baze maestros sublimados / del pintar, I, I, 13. A este don tan sublimado, I, II, 16. Por el legado $y$ gente sublimada, III, VII, 7. Hizo aquí su renombre sublimado, III, VII, 46.

\section{supérfluo}

'Supererogatorio', 'no obligado'. Que los viejos cansados ayudaban / con limosnas supérfluas que allí daban, I, III, 21.

\section{superiora}

Femenino de superior. $Y$ sobre ellos superiora / Madama General Gobernadora, I, II, 12. Superiora es nuestra guarnición, II,
I, 45. La respecta como a superiora, I, II, 29.

\section{susurro}

'Ruido suave'. Qual susurro de abexas enojadas, III, VI, 26.

\section{talar}

'Dícese del traje que llega a los talones'. Una ropa thalar de colorado, III, I, 23.

\section{tanda}

'Tarea', 'encargo'. Y al Conde de Hornos diósele por tanda / almirante en la mar, I, II, 12.

\section{tanto}

'Copia de un escrito'. Diré lo que la carta assí dezía, / de francés, como aquí se trasladaba, I el tanto de la qual es lo siguiente, III, VII, 11.

El Dicc. Aut. documenta este significado en J. Cáncer (1651).

\section{tarántides}

'Tarántula'. Escorpiones ponçoñosos, / tarántides ni la áspide, I, I, 38 .

\section{tenebregura}

'Tiniebla', 'obscuridad'. [Con el bumo de la artillería] quedan los nuestros en tenebregura, I, VIII, 39.

Figura en el Dicc. Acad., aunque nunca ha debido de ser palabra corriente. Solamente conozco otros dos testimonios: Este perverso Satán / me trae en tenebreguras ( $L a$ esposa de los Cantares, 225, en Colección de autos... Ed. de L. Rouanet. Ma- 


\section{F. GoNZÁlez Oi.lé}

drid, 1901, III, 220). Alguna claridad viniera entre tanta tenebregura (J. de Segura, Proceso de cartas de amores [1548]. Madrid, 1956, 40).

\section{terrero}

'Blanco para tirar'. Que la necesidad será terrero / y excusa, I, $\mathrm{V}, 107 v$. Los nuestros tiraban al terrero / con sus moxquetes siempre muy certero, III, II, 72.

\section{trinchea}

'Trinchera'. De un fuerte y con trincheas se ban armado, I, IV, 15.

Esta forma es la adaptación inmediata de la correspondiente palabra francesa. El derivado atrincheado figura en la documentación de revellin (cfr.).

\section{trineo}

'Vehículo sin ruedas que se desliza por yelo y nieve'. Juntaron de trineos gran cuadrilla. / Este es un instrumento así llamado [...] Y en cada ingenio por el yelo bechado / seis bombres iban puestos, II, VI, 42.

No conozco testimonios antiguos. El Dicc. Aut. documenta la variante treno en Quevedo.

\section{tunda}

'Quebranto bélico'. [Los soldados rechazados] todos van buyendo / muy espantados, pues, de ver la tunda, I, VIII, 35.

\section{ultra}

1. 'Al otro lado', 'más allá'. $Y$ al pais de Lanburque la lle- varon, / ultra Musa, donde fueron aloxados, III, IV, 29.

2. 'Además'. Carne para el gusto muy sabrosa / ultra de ser muy grasa, I, I, 42. Ultra desto, también el cargo dieron, I, II, 11. Ultra las diez ciudades, granjerias, I, V, 29.

Es muy frecuente en el poema: I, I, 19; I, I, 45; I, VII, 14; II, $\mathrm{XV}, 10$, etc.

\section{urca}

'Embarcación de determinada especie'. Hecba la embarcación acompañado / del de Orange, con otra mucha gente / $y$ con más de cien urcas rodeado, III, I, 15.

Corominas cree que viene del neerl. bulke, a través del francés.

\section{urgente}

'Apremiante'. Remediando una causa tan urgente, III, VIII, 12.

\section{verberrear}

'Bullir'. Y salió de aquel cuello una gran fuente / de sangre berberreando muy caliente, I, VII, 69.

No conozco ningún otro testimonio de esta palabra. Probablemente es variante expresiva del cultismo, también raro, verberar 'azotar', 'batir'.

\section{villaje}

'Pueblo pequeño'. La gente francesa se extendía / por los villajes, donde es su aposento, III, II, 1 . 


\section{volcán}

'Abertura de la superficie terrestre por donde salen materias ígneas'. [Los disparos de los cañones] no bazen otra cosa / que imitar a volcán cuando rebosa, II, XI, 3.

\section{volteador}

'Volatinero'. El suelo de alombras adornaron, / donde bolteadores fiesta bazian, III, I, 30 .

\section{xixota}

'Nada o cosa que poco importa', según el Dicc. Aut., que la considera voz burlesca y atestigua con Quevedo. Sin tomar, ni robar, ni se consiente, I tan sola una xixota ni otra cosa, / aun- que fuese más rica ni preciosa, III, IV, 13.

Como chichota 'pizca, parte mínima de una cosa', subsiste en el Dicc. Acad. Derivado de cbicha 'carne'. Compárese actual, familiar, de cbicha y nabo 'de poca importancia, despreciable'.

\section{zanja}

Cfr. anja.

\section{zumbo}

'Lo mismo que zumbido, pero menos usado', según Dicc. Aut., que no lo documenta. El clarín por su orden declaraba / ser español el zumbo, II, XI, 4.

F. GONZÁLEZ OLLÉ 
